\title{
The in Vivo Effect of Bilirubin and Sulfisoxazole on Cerebral Oxygen, Glucose, and Lactate Metabolism in Newborn Piglets
}

\author{
BENJAMIN S. BRANN IV,' BARBARA S. STONESTREET, WILLIAM OH, AND \\ WILLIAM J. CASHORE \\ Department of Pediatrics, Women and Infants Hospital of Rhode Island and the Department of Pediatrics, \\ Brown University Program in Medicine, Providence, Rhode Island 02905
}

\begin{abstract}
Bilirubin inhibits in vitro oxidative phosphorylation and glycolysis. This study investigated the in vivo effect of bilirubin on cerebral oxygen, glucose, and lactate uptake in newborn piglets. Seventeen 2- to 4-dayold piglets were divided into three groups and examined as follows: group $1=$ control $(C)$; group $2=$ control with sulfisoxazole; and group $3=$ experimental, given bilirubin with sulfisoxazole. In the experimental group, bilirubin was infused for $4 \mathrm{~h}$. The cerebral bilirubin content in the bilirubin-infused group was $11.0 \pm 1.4 \mathrm{nmol} / \mathrm{g}$ of cerebral cortex (mean \pm SEM), consistent with levels found in infants with kernicterus. However, this level of brain bilirubin had no major, acute effects on cerebral uptake of oxygen, glucose, or lactate despite producing lethargy and ataxia which were consistent with bilirubin intoxication. This suggests that mitochondrial changes may not be involved in vivo in acute bilirubin encephalopathy. (Pediatr Res 22: 135-141, 1987)
\end{abstract}

\section{Abbreviations}

C, control

$\mathrm{CS}$, control with sulfisoxazole

E, experimental

The biochemical mechanism of bilirubin toxicity has been extensively investigated. However, there is no uniformly accepted explanation of its effect. Since the initial report of the inhibition of brain respiration in vitro (1), investigation has been concentrated on the mitochondrial effects of bilirubin. Various mitochondrial preparations and tissue culture techniques have demonstrated in vitro inhibition of cellular respiration, oxidative phosphorylation, glycolysis, protein metabolism, and lipid metabolism by unconjugated bilirubin (2). Many of these studies used pharmacological concentrations of bilirubin with tissues obtained from adult animals.

In vivo investigations of the biochemical toxicity of bilirubin include studies by Schenker et al. (3) on hepatic enzyme phosphorylation and respiration, and various biochemical (4-7) and ultrastructural studies (8-11) of the brain in animal models. Abnormalities in glycolysis, oxidative phosphorylation, and mi-

Received August 14, 1986; accepted February 19, 1987.

Correspondence and for reprint requests William J. Cashore, M.D., 101 Dudley Street, Providence, RI 02905.

Supported in part by Training Grant 1 T32-HD-07232, National Institute of Child Health and Human Development, Bethesda, MD.

' Present address Department of Pediatrics, University of New Mexico, School of Medicine, Albuquerque, NM 87106. tochondrial structure have been shown in brains from rats, guinea pigs, and newborn rabbits studied by various experimental techniques. Some investigations suggest a primary mitochondrial effect of bilirubin as the etiology of cellular toxicity $(1,8-10)$, while others suggest alternate sites of toxicity $(6,11)$. Studies in vivo by Diamond and Schmid (6) have particularly emphasized that bilirubin toxicity may involve pathways other than uncoupling of mitochondrial oxidative phosphorylation. They observed ataxia and seizures in young guinea pigs given unconjugated bilirubin, even though normal oxidative phosphorylation was maintained in freshly prepared brain mitochondria from the same animals. More recently, toxic effects of bilirubin on cerebral glucose metabolism have been suggested by observations in young rats of impaired glycolysis and increased brain glycogen content $(4,5)$, and in newborn rabbits of decreased phosphorylation of protein kinase (7).

Based on these earlier findings in vitro and in vivo, we speculated that bilirubin, when deposited in the brain, may alter rates of cerebral oxygen, glucose, and lactate uptake and consumption. The purpose of this study was to investigate the acute effect of unconjugated bilirubin on in vivo cerebral uptake of oxygen, glucose, and lactate in newborn piglets.

\section{MATERIALS AND METHODS}

Animal preparation. Seventeen newborn piglets, between 2 and 5 days of age, were obtained from a local hog breeder. The piglets remained with the sow until the morning of surgery. Surgery for catheter placement was performed under an infant radiant warmer. Anesthesia consisted of $70 \%$ nitrous oxide and $30 \%$ oxygen administered via a head hood and local lidocaine (1\%) anesthesia. Using sterile techniques, catheters were inserted into 1) the left ventricle via the left common carotid, for microsphere injection, 2) the midthoracic aorta via a femoral artery for reference blood sample withdrawal and arterial oxygen content, glucose, and lactate measurements, 3) the superior sagittal sinus for venous oxygen content and glucose and lactate measurements, 4) the contralateral femoral artery for measurement of mean arterial blood pressure, heart rate, and arterial blood gases, and 5) a femoral vein for blood replacement. Placement of the left ventricular catheter was confirmed by pressure tracing and inspection at autopsy. At the conclusion of surgery, the piglet received an infusion of $D_{10} \mathrm{~W}(5 \mathrm{ml} / \mathrm{kg})$ to prevent hypoglycemia (12). All blood losses during surgery were replaced with blood from a donor pig less than 1 month of age. Postoperatively, kanamycin $(15 \mathrm{mg} / \mathrm{kg})$ and oxacillin $(50 \mathrm{mg} / \mathrm{kg})$ were administered intravenously. The catheters were then filled with heparin $(1000 \mathrm{U} / \mathrm{ml})$ and secured in a gauze pouch to the animal.

Once the animal recovered from anesthesia, gavage feeding $(30 \mathrm{ml} / \mathrm{kg})$ with an artificial pig milk replacer (Land-O-Lakes, 
Co., Minneapolis, MN) was begun and repeated every $4 \mathrm{~h}$. The piglets were allowed an 18-h stabilization period, and were fed 1 $\mathrm{h}$ prior to study.

Experimental protocol. One h prior to study, the piglet was placed in a closed cardboard box to minimize external stimuli, because stimulation has been shown to change cerebral blood flow in piglets (13). The catheters were exteriorized through a small opening in the box. The study design is shown in Figure 1.

The subjects were divided into three groups: 1) $\mathrm{C},(n=5$, weight $=1.29 \pm 0.2 \mathrm{~kg}$, mean $\pm \mathrm{SEM}), 2) \mathrm{CS},(\mathrm{n}=5$, weight $=$ $1.30 \pm 0.2 \mathrm{~kg}$, mean $\pm \mathrm{SEM})$, and 3$) \mathrm{E},(n=7$, weight $1.31 \pm$ $0.1 \mathrm{~kg}$, mean $\pm \mathrm{SEM})$. Following the stabilization period, the $\mathrm{C}$ and CS groups received a buffered solution of $18.5 \%$ of $0.1 \mathrm{~N}$ $\mathrm{NaOH}, 44.5 \%$ of $5 \%$ human albumin (Armour Pharmaceutical Company, Kankakee, IL), and $35 \%$ of $0.055 \mathrm{M}$ sodium phosphate buffer $\left(\mathrm{Na}_{2} \mathrm{HPO}_{4}, \mathrm{pH}=7.3\right)$ by volume. This was administered as a bolus $(8 \mathrm{ml} / \mathrm{kg})$ followed by a continuous infusion $(6$ $\mathrm{ml} / \mathrm{kg}$ ). The $\mathrm{E}$ group received a bolus and continuous infusion of the same buffer with $3 \mathrm{mg} / \mathrm{ml}(0.005 \mathrm{mmol} / \mathrm{ml})$ of bovine bilirubin (Sigma Chemical Corporation, St. Louis, MO). The pH of the buffer and buffer plus bilirubin preparations were adjusted to a physiologic range $(\mathrm{pH}=7.44 \pm 0.11$, mean \pm SEM) utilizing a $0.1 \mathrm{~N} \mathrm{HCl}$ solution. The experimental group received a total bolus of $23 \mathrm{mg} / \mathrm{kg}(0.039 \mathrm{mmol} / \mathrm{kg})$ and a continuous infusion of $19 \mathrm{mg} / \mathrm{kg} / \mathrm{h}(0.033 \mathrm{mmol} / \mathrm{kg} / \mathrm{h})$ of bovine bilirubin. All bilirubin solutions were prepared in a darkened room. During the study period, all buffer or buffer plus bilirubin solutions were shielded from light with aluminum foil. Measurements were made during baseline, and $1,2,3$, and $4 \mathrm{~h}$ after the buffer or buffer plus bilirubin bolus. Measurements were made prior to sulfisoxazole boluses in all cases. All animals in the CS and E groups received a total of $0.9 \mathrm{mmol} / \mathrm{kg}(84 \mathrm{mg} / \mathrm{kg})$ of sulfisoxazole diolamine (Roche Laboratories, Nutley, NJ) in three divided doses at 1,2 , and $3 \mathrm{~h}$ of study. This dose of sulfisoxazole is known to almost maximally displace bilirubin from its albumin binding sites (14).

At the termination of the study, each piglet was observed for its tone, ability to stand, and ability to walk. Following this, the piglet was anesthetized with nitrous oxide and local infiltration

\section{STUDY DESIGN}

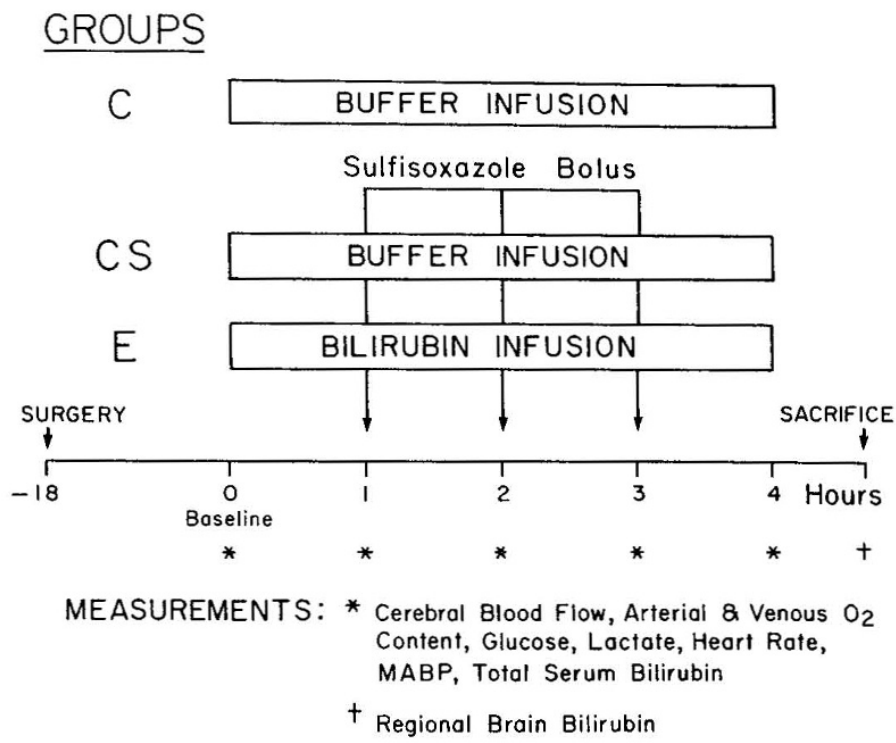

Fig. 1. Study design for buffer or bilirubin infusion and measurement of cerebral $\mathrm{O}_{2}$ and glucose consumption in piglets. of $1 \%$ lidocaine. A polyvinyl catheter was then placed in the right carotid artery. The animal was then sacrificed by an overdose of intravenous sodium thiamylal and saturated potassium chloride. To reduce the likelihood of tissue oxidation of bilirubin and to remove the blood from the cerebral vasculature the brain was perfused in situ with cold $\left(4^{\circ} \mathrm{C}\right)$ isotonic saline at $60 \mathrm{~mm} \mathrm{Hg}$ for $15 \min (15)$.

Immediately after the perfusion, an autopsy was performed on each animal to confirm catheter placement and for removal of the brain, which was separated from the spinal cord at the level of the foramen magnum, divided into right and left hemispheres, and placed in ice. Each hemisphere was weighed; one was used for cerebral blood flow determinations, and the contralateral hemisphere for bilirubin assay. The hemispheres used for the blood flow determinations and measurement of bilirubin content were alternated between experiments. Each hemisphere was divided into four sections: cerebral cortex, cerebellum, pons/midbrain/medulla, and diencephalon.

Methodology and analytic methods. Regional brain blood flow was determined by the technique of Heymann et al. (16) with microspheres $\left(15 \pm 5 \mu\right.$ m diameter) labeled with ${ }^{103} \mathrm{Ru},{ }^{57} \mathrm{Co}$, ${ }^{113} \mathrm{Sn},{ }^{46} \mathrm{Sc},{ }^{51} \mathrm{Cr}$, or ${ }^{95} \mathrm{Nb}$ (New England Nuclear, Boston, MA). Approximately $6 \times 10^{5}$ microspheres, suspended and continuously agitated in $2 \mathrm{ml}$ of $10 \%$ dextran and $0.01 \%$ Tween 80 , were injected and flushed with $2 \mathrm{ml}$ of normal saline into the left ventricle within $45 \mathrm{~s}$. Reference blood samples were collected continuously for $2 \mathrm{~min}$, beginning $15 \mathrm{~s}$ before microsphere injection, and were obtained using a constant withdrawal pump (Harvard Apparatus no. 940, Millis, MA) at a rate of $1.03 \mathrm{ml} /$ min. In order to maintain a constant hematocrit, blood losses from the study sampling were replaced with blood from a donor piglet less than 1 month of age. All brain tissue samples were placed in counting vials to a height of $1 \mathrm{~cm}$. The radioactivities of blood and tissue samples were determined in a gamma well counter (Tracor Analytic model 1185, Elk Grove Village, IL) connected with a multichannel pulse-height analyzer (Canberra model 4203, Meriden, CT). Brain blood flow was calculated with a Digital PdP-11/34 computer (Digital Equipment Corp., Maynard, MA) using the equation (16):

brain blood flow

$$
=\frac{\text { tissue } \mathrm{CPM} \times \text { rate of withdrawal of reference blood }}{\mathrm{CPM} \text { of reference blood }}
$$

All blood and tissue samples contained sufficient microspheres to ensure a blood flow accuracy to within $10 \%$ (16).

Arterial whole blood $\mathrm{pH}$ and blood gas tensions were measured on a Corning 175 blood gas analyzer (Corning Scientific, Medford, MA). Oxygen content was determined in duplicate with the Lex- $\mathrm{O}_{2}$-Con (Lexington Instruments, Waltham, MA). Mean arterial blood pressure and heart rate were measured continuously with a pressure transducer (Hewlett-Packard model $1280 \mathrm{c}$, Waltham, MA) and recorded on a polygraph (Hewlett-Packard model 7754A). Total serum bilirubin was measured by Martinek's modification of the diazo method of Malloy and Evelyn (17). Serum albumin was determined by a Bromcresol Green assay (18). The regional brain bilirubin contents were measured with a modified diazo technique after choroform extraction (19). An enzymatic method was used to determine the serum lactate (20). Colorimeteric assays were performed on a single beam spectrophotometer (Gilford model 240, Oberlin, OH). Serum glucose concentrations were measured by the glucose oxidase method on a YSI Glucose Analyzer (model 23A, Yellow Springs Instruments Co., Yellow Springs, OH)

Data analysis. Cerebral metabolite (oxygen, glucose, and lactate) extraction and uptake were calculated utilizing the Fick principle, 
where:

cerebral metabolite uptake $=$ brain blood flow

$$
\times \text { (arterial metabolite concentration }
$$

- venous metabolite concentration)

and:

cerebral metabolite extraction $=$

(arterial metabolite concentration

- venous metabolite concentration)

arterial metabolite concentration

Brain blood flow was expressed as $\mathrm{ml} \cdot \mathrm{min}^{-1} \cdot \mathrm{g}^{-1}$. Cerebral metabolite uptakes were presented as $\mu \mathrm{mol} \cdot \min ^{-1} \cdot \mathrm{g}^{-1}$, and metabolite extraction as the ratio of the arteriovenous difference to the arterial concentration. All cerebral metabolite uptakes were calculated utilizing the total cerebral blood flow. A negative value for the uptake indicated a net production of that metabolite. Total brain bilirubin content data were presented as nmol/g.

Analysis of variance for repetitive measures and the Dunnett's post hoc test were performed to analyze sequential data within groups (21). Analysis of data between groups was by unpaired $t$ test with the Bonferroni correction (22). To determine the effect of sulfisoxazole on cerebral metabolism, measurements from the two $\mathrm{C}$ groups were compared. The effect of bilirubin on cerebral metabolism was analyzed by comparison of the E group and the $\mathrm{CS}$ group. All values were expressed as mean \pm SEM.

\section{RESULTS}

Table 1 summarizes the $\mathrm{pH}, \mathrm{PaO}_{2}, \mathrm{PaCO}_{2}$, base excess, heart rate, mean arterial blood pressure, and hematocrit measurements of the study groups. The arterial $\mathrm{pH}, \mathrm{PaO}_{2}, \mathrm{PaCO}_{2}$, and heart rate values remained unchanged during the studies. Decreases in the mean arterial blood pressure were observed in the control with sulfisoxazole and experimental groups during the studies, but remained within normal limits for newborn piglets. A small but significant decrease in the hematocrit was noted in the CS group at $4 \mathrm{~h}$. There were no changes in arterial oxygen content within the groups and no differences between groups (data not shown).

The total serum bilirubin levels achieved in the experimental group are shown in Table 2 . These increases were different both from the baseline value in the experimental group and from the $\mathrm{CS}$ group at $1,2,3$, and $4 \mathrm{~h}$. The serum albumin concentration rose from baseline to the end of the study in all groups, because the buffer solution contained $5 \%$ human albumin to stabilize the bilirubin solution.

All brains from the experimental piglets showed diffuse yellow staining at autopsy, both superficially and on cut sections. All regions were stained, with slightly deeper staining in the cerebellum and brainstem than in the cerebral hemispheres, as was also noted in a previous study (23). Grossly, we could not detect discrete staining of the basal ganglia. Histologic examination of these specimens was not done.

Table 3 shows the bilirubin content of the frontal and occipital cerebral cortex in the bilirubin-infused group compared with the

Table 1. Blood gases, hematocrit, and hemodynamic values in three groups of newborn piglets (mean $\pm S E M)^{*}$

\begin{tabular}{|c|c|c|c|c|c|c|}
\hline & & & & lirubin or buffer bolus & infusion & \\
\hline & & 0 & & 2 & & \\
\hline & & Baseline & 1 & Time (h) & 3 & 4 \\
\hline $\mathrm{pH}$ & $\mathrm{C}$ & $7.46 \pm 0.01$ & ND & $7.48 \pm 0.01(n=4)$ & ND & $7.48 \pm 0.03(n=4)$ \\
\hline & $\mathrm{CS}$ & $7.49 \pm 0.01$ & ND & $7.48 \pm 0.01$ & ND & $7.47 \pm 0.02$ \\
\hline & $\mathrm{E}$ & $7.46 \pm 0.04$ & ND & $7.50 \pm 0.01(n=6)$ & ND & $7.48 \pm 0.01$ \\
\hline $\mathrm{PaO}_{2}(\mathrm{~mm} \mathrm{Hg})$ & $\mathrm{C}$ & $96 \pm 5$ & ND & $88 \pm 4(n=4)$ & ND & $89 \pm 6(n=4)$ \\
\hline & $\mathrm{CS}$ & $80 \pm 7$ & ND & $82 \pm 6$ & ND & $89 \pm 6$ \\
\hline & $\mathrm{E}$ & $80 \pm 6$ & ND & $87 \pm 7(n=6)$ & ND & $88 \pm 6$ \\
\hline $\mathrm{PaCO}_{2}(\mathrm{~mm} \mathrm{Hg})$ & $\mathrm{C}$ & $40 \pm 2$ & ND & $40 \pm 2(n=4)$ & ND & $39 \pm 3(n=4)$ \\
\hline & $\mathrm{CS}$ & $43 \pm 4$ & ND & $42 \pm 4$ & ND & $41 \pm 3$ \\
\hline & $\mathrm{E}$ & $37 \pm 2$ & ND & $33 \pm 1(n=6)$ & ND & $36 \pm 1$ \\
\hline $\mathrm{BE}$ (mEq/liter) & $\mathrm{C}$ & $5.4 \pm 2$ & ND & $6.5 \pm 0.8(n=4)$ & ND & $5.9 \pm 0.3(n=4)$ \\
\hline & $\mathrm{CS}$ & $10.1 \pm 3.0(n=3)$ & ND & $7.2 \pm 1.7(n=4)$ & ND & $6.0 \pm 1.3 \dagger(n=4)$ \\
\hline & $\mathrm{E}$ & $2.5 \pm 2.1(n=6)$ & ND & $3.0 \pm 1.0(n=6)$ & ND & $4.6 \pm 1.0$ \\
\hline Heart rate (beats/ & $\mathrm{C}$ & $214 \pm 15$ & $211 \pm 15$ & $220 \pm 17$ & $203 \pm 8$ & $211 \pm 20(n=4)$ \\
\hline $\min )$ & $\mathrm{CS}$ & $247 \pm 24$ & $268 \pm 19$ & $253 \pm 19$ & $256 \pm 21$ & $247 \pm 20$ \\
\hline & $\mathrm{E}$ & $251 \pm 8(n=5)$ & $225 \pm 8$ & $242 \pm 6(n=6)$ & $251 \pm 10(n=6)$ & $242 \pm 8$ \\
\hline Mean arterial & $\mathrm{C}$ & $75 \pm 3$ & $76 \pm 5$ & $81 \pm 5$ & $77 \pm 4$ & $71 \pm 3(n=3)$ \\
\hline blood pressure & $\mathrm{CS}$ & $68 \pm 4$ & $72 \pm 4$ & $60 \pm 4 \dagger, \ddagger$ & $60 \pm 4 \dagger$ & $59 \pm 3 \dagger, \ddagger$ \\
\hline$(\mathrm{mm} \mathrm{Hg})$ & $\mathrm{E}$ & $67 \pm 6$ & $67 \pm 6$ & $63 \pm 4$ & $59 \pm 4 \dagger$ & $55 \pm 3 \dagger$ \\
\hline Hematocrit (\%) & $\mathrm{C}$ & $24 \pm 1$ & $25 \pm 1$ & $25 \pm 1$ & $25 \pm 1$ & $24 \pm 1(n=4)$ \\
\hline & $\mathrm{CS}$ & $23 \pm 1$ & $23 \pm 1$ & $21 \pm 1$ & $22 \pm 1(n=4)$ & $21 \pm 1 \dagger, \ddagger$ \\
\hline & $\mathrm{E}$ & $20 \pm 1$ & $21 \pm 1$ & $20 \pm 1$ & $20 \pm 1$ & $19 \pm 1$ \\
\hline
\end{tabular}

${ }^{*} \mathrm{C}$, control group, $n=5$ unless noted in parentheses; CS, control group with sulfisoxazole, $n=5$ unless noted in parentheses; E, experimental group, $n=7$ unless noted in parentheses; ND, not done.

$\dagger p<0.05$ compared to baseline.

$\ddagger p<0.05$ compared to group $\mathrm{C}$ at corresponding time. 
Table 2. Total serum bilirubin ( $\mu \mathrm{mol} / \mathrm{dl})$ and albumin concentrations $(\mu \mathrm{mol} / \mathrm{dl})$ in study piglets*

\begin{tabular}{llcccc}
\hline & \multicolumn{5}{c}{ Bilirubin or buffer bolus + infusion } \\
\cline { 2 - 6 } & $\begin{array}{c}0 \\
\text { Baseline }\end{array}$ & 1 & $\begin{array}{c}2 \\
\text { Time }(\mathrm{h})\end{array}$ & 3 & 4 \\
\hline Total serum bilirubin & & & & \\
C & $1.0 \pm 0.5$ & $1.0 \pm 0.5$ & $0.9 \pm 0.2$ & $1.0 \pm 0.5$ & $1.9 \pm 0.7(n=4)$ \\
CS & $1.0 \pm 0.5$ & $0.9 \pm 0.2$ & $0.7 \pm 0.2$ & $0.7 \pm 0.2$ & $1.0 \pm 0.2$ \\
E & $0.7 \pm 0.2$ & $21.6 \pm 3.6 \dagger \neq$ & $19.3 \pm 2.9 \dagger, \ddagger$ & $22.4 \pm 3.1 \dagger, \ddagger$ & $27.1 \pm 2.7 \dagger, \ddagger$ \\
Total serum albumin & & & & & \\
C & $20.6 \pm 4.5$ & ND & ND & ND & $27.1 \pm 4.5 \dagger$ \\
CS & $24.2 \pm 3.0$ & ND & ND & ND & $30.4 \pm 3.0 \dagger$ \\
E & $23.0 \pm 3.0(n=6)$ & ND & ND & ND & $28.7 \pm 3.0 \dagger(n=6)$ \\
\hline
\end{tabular}

${ }^{*} \mathrm{C}$, control group, $n=5$ unless otherwise noted in parentheses; CS, control group with sulfisoxazole, $n=5$ unless otherwise noted in parentheses;

$\mathrm{E}$, experimental group, $n=7$ unless otherwise noted in parentheses; ND, not done.

$\dagger p<0.005$ compared to baseline.

$\ddagger p<0.005$ compared to group CS at corresponding time.

Table 3. Regional brain bilirubin contents (nmol/g of brain) in study subjects (mean \pm SEM)

\begin{tabular}{lcc}
\hline & $\begin{array}{c}\text { Frontal } \\
\text { cortex }\end{array}$ & $\begin{array}{c}\text { Occipital } \\
\text { cortex }\end{array}$ \\
\hline Bilirubin content & & \\
C & $0.5 \pm 0.2$ & $0.7 \pm 0.2$ \\
CS & $1.0 \pm 0.3$ & $1.2 \pm 0.3$ \\
E & $11.0 \pm 1.4^{*}$ & $11.6 \pm 1.4^{*}$ \\
\hline
\end{tabular}
CS.

${ }^{*} p<0.05$ compared to corresponding brain regions in groups $\mathrm{C}$ and

control groups. Significant amounts of bilirubin were deposited in both areas of the cerebral cortex.

Table 4 summarizes the oxygen, glucose, and lactate uptakes, and the blood flow to the cortex of each study group. There were no changes in the cerebral blood flow during the studies in the three groups. A significant decrease in the cerebral oxygen uptake compared with the baseline value was observed at the final study determination in the CS group. The baseline oxygen uptake was slightly higher in this group compared with the other groups, although significant differences among groups were not observed. There were no changes in lactate uptake throughout the study in the three groups and no differences among the groups. The glucose uptake of the CS group increased significantly over baseline at the 3-h measurement.

Figure 2 illustrates the significant decreases in the serum arterial glucose concentrations that occurred in all groups over the duration of the study. These decreases were similar among the three groups.

Figure 3 illustrates the changes in the cerebral glucose extraction that occurred in the three groups. An increase in extraction was observed at 2,3 , and $4 \mathrm{~h}$ in the $\mathrm{C}$ group and at 2 and $3 \mathrm{~h}$ in the CS group. No significant increase in glucose extraction was noted in the E group.

All piglets that received bilirubin were lethargic and ataxic at the end of the study period, and were unable to stand. In contrast, animals in the $\mathrm{C}$ and CS groups were not lethargic and were able to walk.

\section{DISCUSSION}

Minor physiologic changes were observed within the three study groups during the 4-h study period. All bood gas values were within the physiologic range previously reported for newborn piglets $(23,24)$. Similarly, the minor reductions in the mean arterial blood pressure were within the normal range previously reported $(23,24)$ and should not alter cerebral blood flow or metabolism. The slight reductions in hematocrit were because of variations in the hematocrit of the replacement blood and the dilutional effect of the solutions used to flush the catheters. This did not result in significant changes in oxygen carrying capacity in these piglets and did not alter brain blood flow, cerebral oxygen uptake, or extraction.

The superior sagittal sinus is the principal venous drainage for the cerebral cortex. In a steady state, the product of arterialvenous metabolite differences and cerebral cortical blood flow provides a sensitive measurement of cerebral cortical metabolism, and this method is the basis for most in vivo quantitative studies of cerebral substrate utilization (25).

Measurements of the cerebral consumption of oxygen, glucose, and lactate have been performed in vivo in fetal sheep (26), infant baboons (27), and newborn piglets (28). The cerebral blood flow and rates of consumption of oxygen and glucose in newborn piglets have been previously demonstrated to be similar to those of human infants $(13,28)$. Although there is a large discrepancy in the actual brain wight and brain weight-to-body weight ratio between newborn piglets and human infants, the brain of the piglet and human newborn both develop perinatally $(29,30)$. As a result of its similarity to the human newborn in brain development, the neonatal pig appears to be a suitable animal model to study the effects of bilirubin on cerebral metabolism.

Even though bilirubin is deposited in even higher concentrations in brain regions other than the cerebral cortex (23), and many of the abnormal neurologic signs in kernicterus are extrapyramidal, if bilirubin has acute toxic effects on mitochondria it may affect the cerebral cortex as well as other brain regions. In our newborn piglets significant bilirubin deposition was achieved (E group), and therefore acute in vivo alterations in cerebral oxygen, glucose, and lactate uptake should reflect this deposition. The amount of bilirubin given to the piglet by bolus and constant infusion was calculated to equal or exceed the estimated binding capacity of the piglet's albumin. As shown in Table 2, the serum bilirubin concentration in the $\mathrm{E}$ group was approximately equimolar to the albumin concentration between 1 and $4 \mathrm{~h}$. With a bilirubin load sufficient to bind with an equimolar amount of albumin, the injected concentration of sulfisoxazole (1 $\mathrm{mM})$ presumably displaced excess bilirubin from its albumin binding sites, producing cerebral bilirubin concentrations similar to those observed in human infants with kernicterus (31).

Despite high cerebral bilirubin concentrations (11.0 \pm 1.4 $\mathrm{nmol} / \mathrm{g}$, mean $\pm \mathrm{SEM})$, no acute effects were observed on cerebral utilization of oxygen, glucose, or lactate. However, all of the piglets that received bilirubin infusions were ataxic or lethargic, findings often associated with acute bilirubin encephalopathy in human infants (32). These abnormal behavioral signs were more likely due to bilirubin toxicity than to reductions in arterial glucose concentrations, because the values observed for arterial glucose concentration remained within the normal range 
Table 4. Oxygen, glucose, lactate uptake, and cerebral blood flow in study subjects (mean \pm SEM)*

\begin{tabular}{|c|c|c|c|c|c|c|}
\hline & & \multicolumn{5}{|c|}{ Bilirubin bolus + infusion } \\
\hline & & 0 & 1 & 2 & 3 & 4 \\
\hline & & Baseline & & & Time $(\mathrm{h})$ & \\
\hline Oxygen & $\mathrm{C}$ & $1.76 \pm 0.32$ & $1.60 \pm 0.29$ & $1.88 \pm 0.40$ & $1.75 \pm 0.29$ & $2.10 \pm 0.32(n=4)$ \\
\hline Uptake & $\mathrm{CS}$ & $2.87 \pm 0.55$ & $2.32 \pm 0.41$ & $2.71 \pm 0.32$ & $2.38 \pm 0.36$ & $1.62 \pm 0.11+(n=4)$ \\
\hline$\left(\mu \mathrm{mol} \cdot \mathrm{min}^{-1} \cdot \mathrm{g}^{-1}\right)$ & $E$ & $2.22 \pm 0.23(n=6)$ & $2.69 \pm 0.46$ & $2.08 \pm 0.24$ & $1.96 \pm 0.26$ & $1.75 \pm 0.16$ \\
\hline Glucose & $\mathrm{C}$ & $0.52 \pm 0.12$ & $0.44 \pm 0.06$ & $0.61 \pm 0.17$ & $0.64 \pm 0.12$ & $0.73 \pm 0.09(n=4)$ \\
\hline Uptake & $\mathrm{CS}$ & $0.52 \pm 0.12$ & $0.53 \pm 0.09$ & $0.76 \pm 0.04$ & $0.82 \pm 0.16 \dagger$ & $0.49 \pm 0.04$ \\
\hline$\left(\mu \mathrm{mol} \cdot \mathrm{min}^{-1} \cdot \mathrm{g}^{-1}\right)$ & E & $0.49 \pm 0.04$ & $0.58 \pm 0.08$ & $0.52 \pm 0.07$ & $0.50 \pm 0.08$ & $0.47 \pm 0.03$ \\
\hline Lactate & $\mathrm{C}$ & $-0.05 \pm 0.06$ & $-0.01 \pm 0.02$ & $-0.09 \pm 0.1$ & $-0.06 \pm 0.05$ & $0.01 \pm 0.06(n=4)$ \\
\hline Uptake & $\mathrm{CS}$ & $-0.12 \pm 0.07$ & $0.01 \pm 0.15$ & $-0.16 \pm 0.09$ & $0.01 \pm 0.08$ & $0.28 \pm 0.26$ \\
\hline$\left(\mu \mathrm{mol} \cdot \mathrm{min}^{-1} \cdot \mathrm{g}^{-1}\right)$ & $\mathrm{E}$ & $0.11 \pm 0.11$ & $0.25 \pm 0.11$ & $-0.11 \pm 0.14$ & $-0.10 \pm 0.16$ & $0.09 \pm 0.06$ \\
\hline Cerebral Cortical & $\mathrm{C}$ & $0.96 \pm 0.14$ & $0.83 \pm 0.16$ & $1.02 \pm 0.16$ & $1.01 \pm 0.14$ & $1.23 \pm 0.13(n=4)$ \\
\hline Blood Flow & $\mathrm{CS}$ & $1.16 \pm 0.21$ & $1.06 \pm 0.18$ & $1.41 \pm 0.11$ & $1.35 \pm 0.21$ & $1.15 \pm 0.11$ \\
\hline$\left(\mathrm{ml} \cdot \min ^{-1} \cdot \mathrm{g}^{-1}\right)$ & $\mathrm{E}$ & $1.09 \pm 0.09$ & $1.18 \pm 0.15$ & $1.23 \pm 0.12$ & $1.09 \pm 0.09$ & $1.09 \pm 0.07$ \\
\hline
\end{tabular}

${ }^{*} \mathrm{C}$, control group, $n=5$ unless otherwise noted in parentheses; CS, control group with sulfisoxazole, $n=5$ unless otherwise noted in parentheses; E, experimental group, $n=7$ unless otherwise noted in parentheses; ND, not done.

$\dagger p<0.05$ compared to baseline.

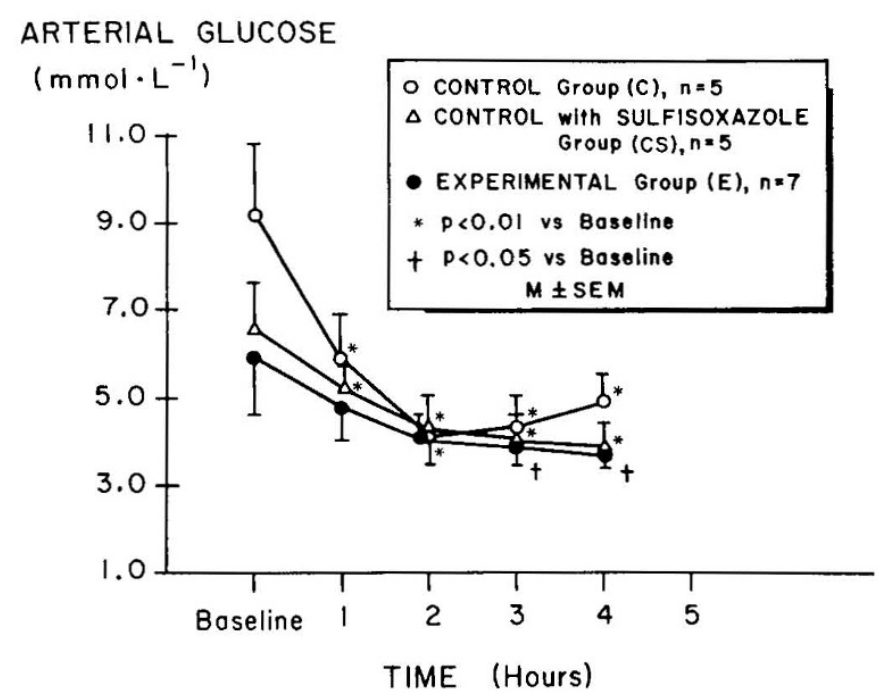

Fig. 2. Serum glucose concentrations from arterial samples during 4$\mathrm{h}$ studies in control and bilirubin-infused piglets.

previously reported in piglets (13). Both control groups responded to the slight decreases in serum glucose with an increase in glucose extraction, so that glucose, oxygen, and lactate uptakes remained normal.

The lack of significant change in oxygen, lactate, and glucose uptakes in the E group suggests that the acute biochemical effect of bilirubin is probably not mitochondrial. This hypothesis is supported histochemically by the study of Chen et al. (11) who demonstrated that bilirubin is first deposited in the dendrites and axons of neurons, rather than in the mitochondria. Although Day (1) demonstrated inhibition of mitochondrial respiration in vitro, Diamond and Schmid (6) were unable to demonstrate uncoupling or inhibition of oxidative phosphorylation in a group of hyperbilirubinemic, lethargic guinea pigs. In their studies, bilirubin contents of $17.8 \mathrm{nmol} / \mathrm{g}$ of brain were obtained after 1 $h$ of exposure, compared to regional brain bilirubin contents of $11.0 \mathrm{nmol} / \mathrm{g}$ in our studies. Our findings are therefore consistent with those of Diamond and Schmid (6), that bilirubin intoxicated experimental animals become lethargic and ataxic despite a lack of measurable changes in glucose oxidation by the brain.

Although remaining within the range of values found in normal piglets by Wootton et al. (13) and in control piglets for this study, both the decrease in serum glucose and the increase in glucose extraction were smaller in our bilirubin-infused group

\section{CEREBRAL GLUCOSE EXTRACTION (RATIO)}

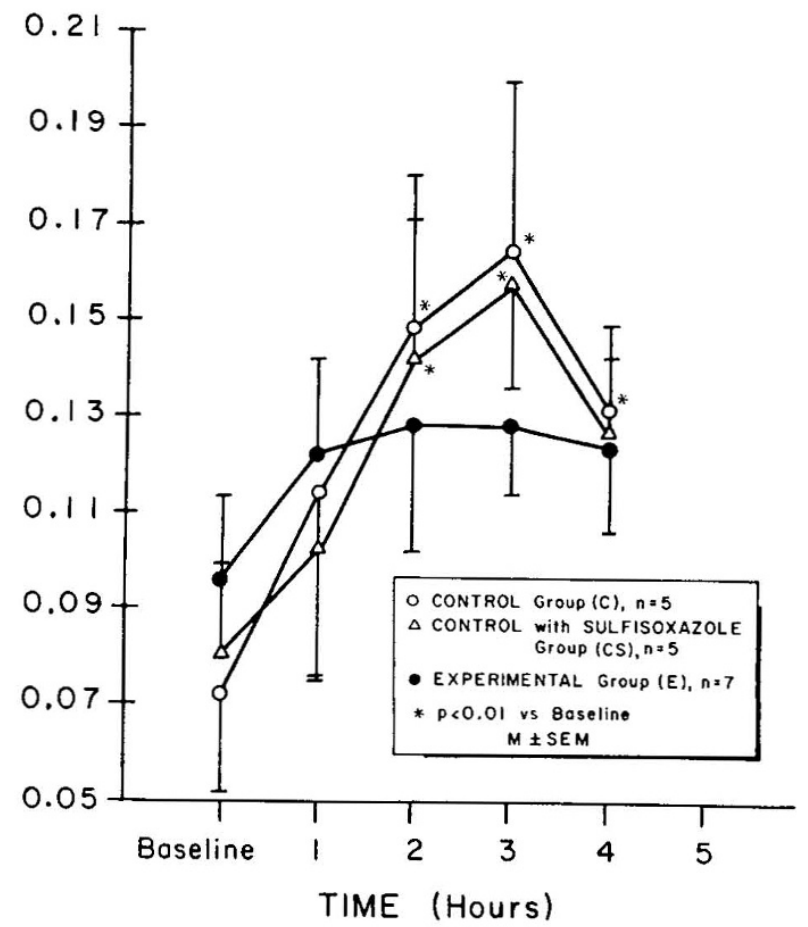

Fig. 3. Cerebral glucose extraction at baseline and during 4-h studies in control and hyperbilirubinemic animals.

than in our $\mathrm{C}$ groups. Glucose uptake across the blood-brain barrier is by a facilitated transport mechanism, for which the rate-limiting step is the phosphorylation of glucose to glucose-6phosphate by the enzyme hexokinase (33). If bilirubin inhibits glucose transport, it may do so at the hexokinase step, since bilirubin has recently been shown to decrease cerebral protein phosphorylation (7). We speculate that this mechanism may be involved in the lack of increase in glucose extraction observed in our hyperbilirubinemic, experimental piglets. However, even the finding of blunted glucose extraction in the $E$ group does not support the interpretation that inhibition of mitochondrial metabolism is the primary effect of bilirubin toxicity in vitro. Despite a smaller increase in the fractional cerebral extraction of glucose for the hyperbilirubinemic E group, the overall rates of glucose 
and oxygen uptake and consumption were similar in all three study groups. The finding that marked neurological and behavioral changes were unaccompanied by comparably large changes in cortical oxygen and glucose consumption supports the conclusion, instead, that the toxic effects of bilirubin noted in this study may involve more peripheral, or at least subcortical, mechanisms rather than marked changes in cortical oxidative metabolism.

Sulfonamides have various neurologic side effects (34), and inhibit carbonic anhydrase (35), an enzyme present in the choroid plexus. Although sulfisoxazole is distributed almost entirely extracellularly (36), it was possible that sulfisoxazole alone would affect cerebral metabolism. To exclude this possibility, control groups were studied, with and without sulfisoxazole. Our results demonstrate no effect of sulfisoxazole on cerebral consumption of oxygen, glucose, or lactate.

Early, and possibly reversible, signs of bilirubin intoxication may not be associated with irreversible changes in mitochondrial oxidative phosphorylation. Our findings do not document a marked change in cortical glucose uptake or lactate production, and the earlier findings of Diamond and Schmid (6) also failed to demonstrate marked changes in brain oxidative phosphorylation in living guinea pigs at similar brain bilirubin concentrations. Early findings consistent with bilirubin toxicity may represent the interference of bilirubin with nerve transmission or conduction. This mechanism would be consistent with the anatomical observations of Chen et al. (11), that the initial locus of bilirubin uptake is in the peripheral part of the nerve cell and in astroglia, rather than in nerve cell bodies. The recent report of Hansen et al. (37), that bilirubin inhibits phosphorylation of Synapsin I in presynaptic vesicles, is also consistent with the hypothesis that impairment of peripheral nerve transmission may occur in the early stages of acute bilirubin toxicity. Irreversible uncoupling of oxidative phosphorylation might represent a later stage of bilirubin toxicity, or a form of toxicity caused by higher local bilirubin concentrations at longer times of exposure.

Acknowledgments. The authors acknowledge the excellent technical assistance of Donna L. Piva, Carol Calista, and Steven Warburton. We also thank Lori Dutra and Lea Gold for their expert preparation of this manuscript.

\section{REFERENCES}

1. Day RL 1954 Inhibition of brain respiration in vitro by bilirubin: Reversal of inhibition by various means. Proc Soc Exp Biol Med 85:261-264

2. Karp WB 1979 Biochemical alterations in neonatal hyperbilirubinemia and bilirubin encephalopathy: a review. Pediatrics 64:361-368

3. Schenker S, McCandless DW, and Wittgenstein E 1966 Studies in vivo of the effect of unconjugated bilirubin on hepatic phosphorylation and respiration. Gut 7:409-414

4. Katoh R, Kashiwamata S, Niwa R 1975 Studies on cellular toxicity of bilirubin: Effect on the carbohydrate metabolism in the young rat brain. Brain Res 83:81-92

5. Kotoh-Semba R 1976 Studies on cellular toxicity of bilirubin: effect on brain glycolysis in the young rat. Brain Res 113:339-348

6. Diamond I, Schmid R 1967 Oxidative phosphorylation in experimental bilirubin encephalopathy. Science 155:1288-1289

7. Morphis L, Constantopoulos A, Matsoniotis N 1982 Bilirubin-induced modulation of cerebral protein phosphorylation in neonate rabbits in vivo. Science 218:156-158

8. Jew JY, Williams TH 1977 Ultrastructural aspects of bilirubin encephalopathy in cochlear nuclei of the Gunn Rat. J Anat 124:599-614

9. Schutta HS, Johnson L 1967 Bilirubin encephalopathy in the Gunn Rat: a fine structure study of the cerebellar cortex. J Neuropathol Exp Neurol 26:377396
10. Schutta HS, Johnson L, Neville HE 1970 Mitochondrial abnormalities in bilirubin encephalopathy. J Neuropathol Exp Neurol 29:296-305

11. Chen HC, Wang CH, Tsan KW, and Chen Y 1971 An electron microscopic and radioautographic study on experimental kernicterus. II. Bilirubin movement within neurons and release of waste products via astroglia. Am J Pathol 64:45-66

12. Goodwin RFW 1957 The relationship between the concentration of blood sugar and some vital body functions in the newborn pig. J Physiol (Lond) 136:208-217

13. Wootton R, Flecknell PA, John M 1982 Accurate measurement of cerebral metabolism in the conscious unrestrained neonatal piglet. Biol Neonate 41:209-220

14. Cashore WJ, Oh W, Brodersen R 1983 Bilirubin-displacing effect of furosemide and sulfisoxazole. Dev Pharmacol Ther 6:230-238

15. Brodersen R, Bartels P 1969 Enzymatic oxidation of bilirubin. Eur J Biochem $10: 468-473$

16. Heymann MA, Payne BD, Hoffman JIE, Rudolph AM 1977 Blood flow measurements with radionucleotide-labelled particles. Prog Cardiovasc Dis 20:55-79

17. Martinek RG 1966 Improved micromethod for determination of serum bilirubin. Clin Chim Acta 13:161-170

18. Doumas BT, Watson WA, Biggs HG 1971 Albumin standards and the measurement of serum albumin with bromcresol green. Clin Chim Acta 31:8796

19. Bratlid D, Winsnes A 1971 Determination of conjugated and unconjugated bilirubin methods based on direct spectrophotometry and chloroform-extraction. A reappraisal. Scand J Clin Lab Invest 28:41-48

20. Loomis ME 1961 An enzymatic fluorometric method for determination of lactic acid in the serum. J Lab Clin Med 57:966-969

21. Winer BJ 1971 Single factor experiments having repeated measures on the same elements. In: Maytham W, Shapiro A, Stern J (eds) Statistical Principles in Experimental Design, 2nd ed. McGraw-Hill Book Company, New York, pp 261-308

22. Wallenstein S, Zucker CL, Fleiss JL 1980 Some statistical methods useful in circulation research. Circ Res 47:1-9

23. Burgess GH, Stonestreet BS, Cashore WJ, Oh W 1985 Brain bilirubin deposition and brain blood flow during acute urea-induced hyperosmolality in newborn piglets. Pediatr Res 19:536-542

24. Hansen NB, Stonestreet BS, Rosenkrantz TS, Oh W 1983 Validity of Doppler measurements of anterior cerebral artery blood flow velocity: correlation with brain blood flow in piglets. Pediatrics 72:526-531

25. Sokoloff L 1960 The metabolism of the central nervous system in vivo. In: Field J, Magoun HW, and Hall VE (eds) Handbook of Physiology - Neurophysiology, vol 3. American Physiological Society, Washington, DC, pp $1843-1864$

26. Tsoulos MG, Schneider JM, Colwill JR, Meschia G, Makowski EL, Battaglia FC 1975 Cerebral glucose utilization during aerobic metabolism in fetal sheep. Am J Physiol 229:235-239

27. Levitsky LL, Fisher DE, Paton JB, Delanney CW 1977 Fasting plasma levels of glucose, acetoacetate, D-beta-hydroxybutyrate, glycerol and lactate in the baboon infant: correlation with cerebral uptake of substrates and oxygen. Pediatr Res 11:298-302

28. Flecknell PA, Wootton R, John M 1982 Accurate measurement of cerebral metabolism in the conscious unrestrained neonatal piglet: (II) glucose and oxygen utilization. Biol Neonate 41:221-226

29. Davison AN, Dobbing J 1968 The developing brain. In: Davison AN, Dobbing J (eds) Applied Neurochemistry. FA Davis Company, Philadelphia, pp 253286

30. Pond WG, Houpt KA 1978 The Biology of the Pig. Cornell University Press, Ithaca, NY

31. Claireaux AE, Cole PG, Lathe GH 1953 Icterus of the brain in the newborn. Lancet 2:1226-1230

32. Van Praagh R 1961 Diagnosis of kernicterus in the neonatal period. Pediatrics 28:870-876

33. Lajtha AL, Maker HS, Clarke DD 1981 Metabolism and transport of carbohydrates and amino acids. In: Siegel GJ, Albers RW, Agranoff BW, Katoman R (eds) Basic Neurochemistry. Little, Brown and Company, Boston, pp 330

34. Weinstein L, Madoff MA, Samet CM 1960 The sulfonamides. N Engl J Med 263:952-957

35. Modge GH 1975 Diuretics and other agents employed in the mobilization of edema fluid. In: Goodman LS, Gilman A (eds) The Pharmacological Basis of Therapeutics, 5th ed. MacMillan Publishing Co. Inc., New York, pp 825

36. Marshall EK Jr 1948 Distribution of 3,4-dimethyl-5-sulfanilamidoisoxazole in body. Proc Soc Exp Biol Med 68:472-473

37. Hansen TWR, Walaas SI, Bratlid D, Greengard P 1986 Effects of bilirubin (B) on phosphorylation of Synapsin I. Pediatr Res 20:462A(abstr) 